\title{
Effects of low-magnitude, high-frequency mechanical stimulation in the rat osteopenia model
}

\author{
S. Sehmisch • R. Galal • L. Kolios • M. Tezval • \\ C. Dullin • S. Zimmer • K. M. Stuermer • E. K. Stuermer
}

Received: 17 November 2008 / Accepted: 9 February 2009/Published online: 13 March 2009

(C) The Author(s) 2009. This article is published with open access at Springerlink.com

\begin{abstract}
Summary In this study, short-term, whole-body vertical vibration at $90 \mathrm{~Hz}$ improved trabecular bone quality. There was an improvement of bone quality and density in both osteoporotic and control rats. This treatment may therefore be an attractive option for the treatment of osteoporosis.

Introduction Aside from pharmacological treatment options, physical exercise is known to augment bone mass. In this study, the effects of whole-body vertical vibration (WBVV) on bone quality and density were evaluated using an osteoporotic rat model.

Methods Sixty female Sprague Dawley rats were ovariectomized (C) or sham (SHAM) operated at the age of 3 months. After 3 months, both groups were divided into two subgroups that received either WBVV at $90 \mathrm{~Hz}$ for 35 days or no treatment. After sacrificing the rats, we evaluated vertebral bone strength, histomorphometric parameters, and bone mineral density (BMD).

Results Treatment with WBVV resulted in improved biomechanical properties. The yield load after WBVV was significantly enhanced. According to yield load and Young's modulus, the treated OVX rats reached the level of the untreated SHAM animals. In all measured histomorphometric parameters, WBVV significantly improved bone density. Treatment with WBVV demonstrated greater
\end{abstract}

S. Sehmisch $(\bowtie) \cdot$ R. Galal $\cdot$ L. Kolios $\cdot$ M. Tezval $\cdot$

K. M. Stuermer $\cdot$ E. K. Stuermer

Department of Trauma Surgery and Reconstructive Surgery,

University of Goettingen,

Robert-Koch-Str. 40,

37075 Goettingen, Germany

e-mail: stephan.sehmisch@med.uni-goettingen.de

C. Dullin $\cdot$ S. Zimmer

Department of Radiology, University of Goettingen,

Goettingen, Germany effects on the trabecular bone compared to the cortical bone. The ash-BMD index showed significant differences between treated and untreated rats.

Conclusion Using WBVV as a non-pharmacological supportive treatment option for osteoporosis demonstrated an enhancement of bone strength and bone mass. This procedure may be an attractive option for the treatment of osteoporosis.

Keywords Mechanical stimuli · Osteoporosis ·

Trabecular bone . Whole-body vibration

\section{Introduction}

Bone is a mechanosensitive tissue that adapts its mass, architecture, and mechanical properties in response to mechanical load. After reaching peak bone mass, there is a decline in bone mass that depends on genetic and hormonal factors, nutrition, physical activity, and lifestyle. Post-menopausal estrogen deficiency accelerates the process of bone loss [1]. To counteract these changes, patients are encouraged to exercise the musculoskeletal system, as mechanical loading is important for the maintenance of bone structure and strength.

The beneficial effects of mechanical loading on bone are not fully understood. Turner et al. [2] stated that osteocytes, osteoblasts, and bone-lining cells are influenced by straininduced alterations in canalicular fluid flow. Then, via different mechanisms, e.g., growth factors, prostaglandins, or other mediators, osteoblasts are locally influenced to increase the production of bone matrix. Osteoprogenitor cells are stimulated to proliferate and differentiate into bone matrix-producing osteoblasts. With the age-related decrease of osteogenic potential, the number of osteoblasts, bone- 
lining cells, and osteoprogenitor cells decreases. Because of these changes, conventional exercise regimens have only marginally improved bone mass in elderly individuals and animals [3].

Mechanical signals that modulate bone metabolism include high-magnitude strain at frequencies ranging from 0.5 to $2 \mathrm{~Hz}$ or strains of low magnitude at high frequencies. Low-magnitude, high-frequency strain stimulates new bone formation in connection to the loading frequency [4-6]. Both cortical as well as trabecular bone were significantly increased in animals when vibration was applied at $90 \mathrm{~Hz}$, while at $45 \mathrm{~Hz}$ there was no effect on either cortical or trabecular bone [7]. These results confirmed the observation that vibration increases bone stiffness and microhardness [8]. The vibratory stimulus on bone was mostly analyzed in the extremities. This non-drug anti-osteoporosis treatment has been shown to be efficient in preventing bone loss of the lower extremity in ovariectomized rats [9].

Osteoporosis primarily affects the trabecular bone (e.g., vertebral body, femoral neck, distal radius, or proximal humerus). Because of their high clinical relevance, lumbar vertebral bodies were chosen for this study. Vertebral fractures are an important clinical indicator of the progression of osteoporosis and the ongoing fracture risk of new osteoporotic fractures, independent of bone mineral density (BMD) [1012]. The mature rat is a standard model for the investigation of morphological and biomechanical changes after different treatments for osteoporosis. In contrast to the upper tibia metaphysis, which is widely studied, the lumbar vertebrae contain both trabecular bone as well as a strong cortical shell $[13,14]$ This region therefore could be an important and interesting area to investigate biomechanical changes after whole-body vibration, which may influence trabecular as well as cortical bone.

The aim of this study was to evaluate the effect of shortterm, low-magnitude, high-frequency vibration at $90 \mathrm{~Hz}$ [7] on the vertebral bodies of normal and ovariectomized rats.

\section{Materials and methods}

Animals and substances

Experiments were performed using 603 -month-old Sprague Dawley rats (Fa. Winkelmann Borken, Germany). Rats were divided into four treatment groups (15 rats each) in which rats were bilaterally ovariectomized (OVX, 30 rats) or sham operated (SHAM, 30 rats) at the age of 3 months. Rats were briefly exposed to $\mathrm{CO}_{2}$ until unconscious and then anesthetized via i.p. injection of $62.5 \mathrm{mg} / \mathrm{kg}$ ketamine (Hostaket ${ }^{\circledR}$, Hoechst) and $7.5 \mathrm{mg} / \mathrm{kg}$ xylazine (Rompun ${ }^{\circledR}$, Bayer). After surgery, rats were left untreated for 3 months. The OVX animals developed osteoporosis during this period.
Three months after surgery, SHAM and OVX rats were placed on a vibration platform (SHAM Vib. and OVX Vib. groups, respectively) and compared to untreated SHAM and OVX rats. Vibration was performed two times a day, each for $15 \mathrm{~min}, 7$ days a week, using a vibration platform with a cage that had the capacity to hold eight rats. The cage was fixed on a rotating current vibration motor that was constructed as cement shaker (Drehstrom-Vibrationsmotor Typ HVL/HVE, Vibra Schultheis, Offenbach, Germany). Rats were allowed to move freely in the cage during vibration. The device worked at a frequency of $90 \mathrm{~Hz}$ and an amplitude of $0.5 \mathrm{~mm}$ (Fig. 1).

Before sacrificing the rats 35 days after surgery, flatpanel volumetric computed tomography (fpVCT) scans were performed under anesthesia. After sacrificing the animals, the lumbar vertebral bodies were cleaned of skin, muscles, and tendons and stored in tubes at $-20^{\circ} \mathrm{C}$ until analysis. The study protocol was approved by the District Government and conforms to German animal protection laws (Az: 509.42502/01-53.03).

\section{Serum analyses}

An electrochemiluminescence immunoassay was performed on blood samples (approximately $0.5 \mathrm{ml}$ ) to measure the level of the anabolic marker osteocalcin and the concentration of alkaline phosphatase, a marker for bone resorption (Roche Diagnostics, Mannheim, Germany).

\section{Biomechanical testing}

Biomechanical testing was used to analyze the resistance to incoming forces on the intact fourth lumbar vertebral body of osteoporotic rats.

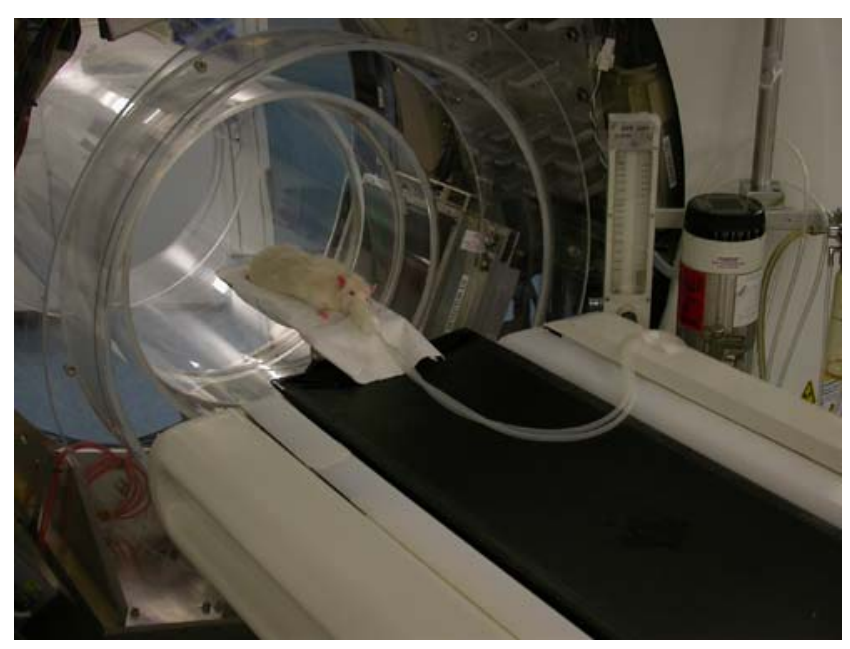

Fig. 1 Flat-panel volume CT prototype constructed by General Electric Global Research (Niskayuna, NY, USA). Scans were performed under isoflurane anesthesia before sacrificing the rats 

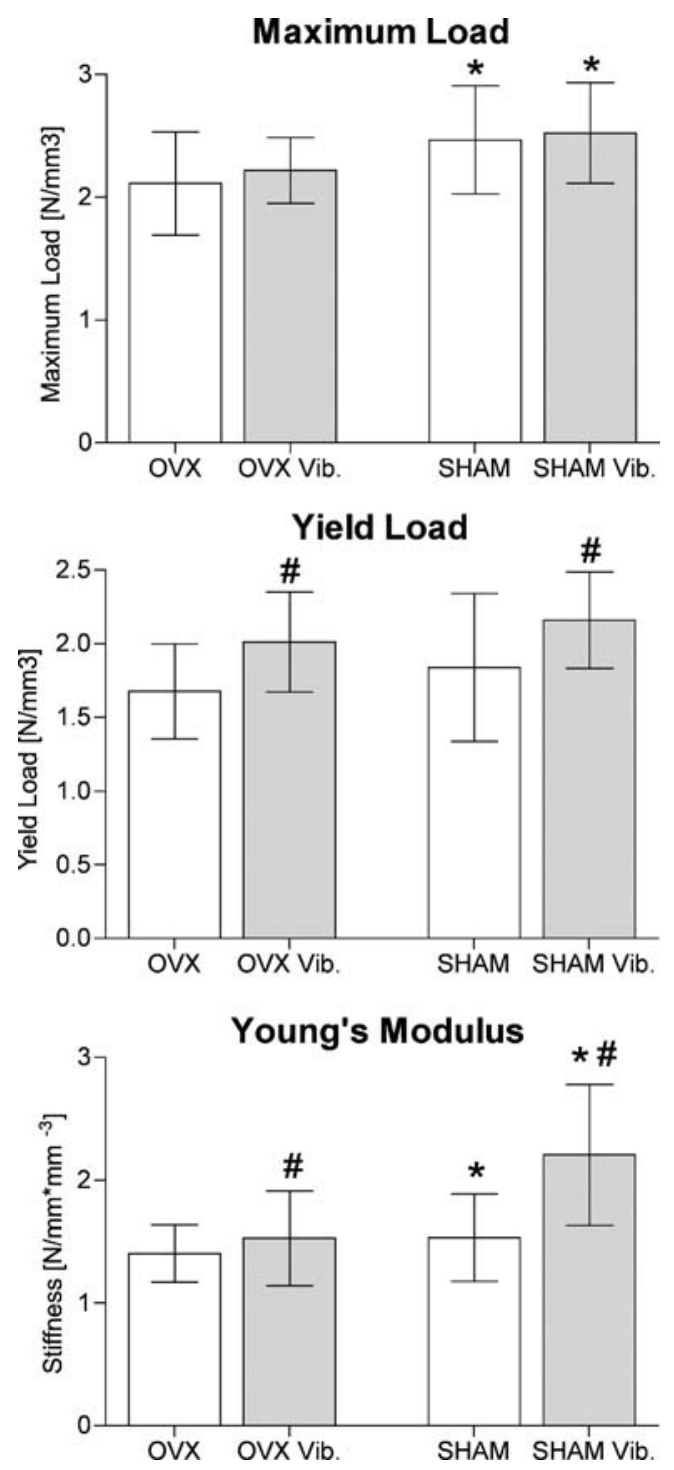

Fig. 2 Results of the biomechanical testing. The $p$ value between treated and untreated animals was calculated using a two-way ANOVA. $p$ values $<0.05$ were considered significant $(* p<0.05$ vs. OVX, $\# p<0.05$ vs. non vib)

The measuring range of the mechanical force was from 2 to $500 \mathrm{~N}$ at a relative accuracy of $0.2-0.4 \% \mathrm{FN}$. The lumbar vertebral body was fixed on the device with a primary force of $1 \mathrm{~N}$. The correct stamp position on the caudal end plate was checked visually and corrected if necessary. Strength admission was recorded with every $0.1 \mathrm{~mm}$ lowering of the stamp using "testXpert" software. The speed of the feed motion was $50 \mathrm{~mm} / \mathrm{s}$. The mechanical test was automatically terminated at a pressure of $500 \mathrm{~N}$ or by compression of more than $3.0 \mathrm{~mm}$.

The maximal compressive strength $\left(F_{\max }\right)$ was determined as the highest strength that the vertebral body could withstand. We used the rise of the graph to calculate the elastic deformation, stiffness, and Young's modulus $(S)$. The yield load $\left(y_{\mathrm{L}}\right)$ of the bone was defined as a decrease of stiffness of more than two standard deviations. This transition point of elastic to plastic deformation represents the $y_{\mathrm{L}}$ of the bone [15] and corresponds to the first microcracks of trabecular bone.

Preparation for microscopy and microradiography

The first lumbar vertebral bodies were defatted and dehydrated in an alcohol series, followed by embedding in methylmetacrylate. After polymerization, the samples were cut into $100 \pm 10$ - $\mu \mathrm{m}$-thick sections in a transversal direction (corresponding to the fpVCT evaluation) using a specifically designed diamond-coated saw with a blade thickness of $350 \mu \mathrm{m}$ (Leica SP 1600 innerhole saw microtome, Bensheim, Germany). Three transversal sections, from the center of each vertebral body, were microradiographed using a Faxitron Xray System (Hewlett-Packard, San Diego, CA, USA) on Kodak professional Industrex SR45 film (100NIF) at a resolution of approximately $0.5 \mu \mathrm{m}$ and an exposure of $10 \mathrm{kV}$ for $3 \mathrm{~min}$ [16].

The analysis presented here is based on a $2 \mathrm{D}$ imaging process. Using the QWin software evaluation protocol (Leica), the examiner was able to define the mineralized bone on the microradiographic images with the aid of the software's grey detection. According the ASBMR nomenclature [17], the following parameters were evaluated: cortical bone volume from total bone volume (Ct.V), trabecular bone area (Tb.Ar.), the number of trabecular nodes (N.Nd.), the trabecular number (Tb.N.), and the average trabecular/strut width (Tb.Wi.).

\section{Intravital fluorochrome labeling}

During the 35 days of treatment, animals were subcutaneously injected with four fluorescent agents (Merck, Darmstadt, Germany) to label the process of bone formation and restoration. The following fluorochromes were used: xylenol orange $(90 \mathrm{mg} / \mathrm{kg})$ on day 13 , calcein green $(10 \mathrm{mg} / \mathrm{kg})$ on day 18 , alizarin red $(30 \mathrm{mg} / \mathrm{kg})$ on day 24 , and tetracycline $(25 \mathrm{mg} / \mathrm{kg}$ ) on day 35 . An additional dose of alizarin red was provided on day 26 to intensify the labeling. The results of the fluorochrome labeling were analyzed in a qualitative and semi-quantitative way. The widths of the different trabecular apposition bands were measured under the microscope. In each slice, two well-defined bands from both the cranial and caudal parts of the vertebral body were measured. The absolute values, the apposition width per day and the relative values were compared.

Flat-panel volumetric computed tomography

The fpVCT used in this study was developed and constructed by General Electric Global Research (Niskayuna, NY, USA) 
(Fig. 2). It consists of a modified circular CT gantry and two amorphous silicon flat-panel X-ray detectors, each $20.5 \times$ $20.5 \mathrm{~cm}^{2}$ with a matrix of $1,024 \times 1,024$ detector elements (each with a size of $200 \times 200 \mu \mathrm{m}^{2}$ ). The fpVCT uses a stepand-shoot acquisition mode. Standard $z$-coverage of one step is $4.21 \mathrm{~cm}$. The rats were placed along the $z$-axis of the system and their lumbar regions scanned in three steps. All datasets were acquired with the same protocol: 1,000 views per rotation, $8 \mathrm{~s}$ rotation time, 360 detector rows, $80 \mathrm{kVp}$ and $100 \mathrm{~mA}$. A modified Feldkamp algorithm in combination with a standard kernel was used for image reconstruction. For every rat, the lumbar spine was reconstructed using $512 \times 512$ matrices with a definite isotropic voxel size of 70 $\mu \mathrm{m}$. The resolutions of the $3 \mathrm{D}$ reconstructions were chosen to be half the resolution of the system for high-density structures, such as bone, in order to avoid additional digitalization artifacts. With the help of dedicated software, the first and second vertebral body volumes, morphologic parameters, and bone mineral densities were calculated [18]. The coefficient of variation (CV) of this instrument is 0.052 .

\section{Ashing}

In order to determine the amount of mineralized bone, the second lumbar vertebral bodies were mineralized at $750^{\circ} \mathrm{C}$ for $48 \mathrm{~h}$ and weighed to the nearest $0.00001 \mathrm{~g}$. The vertebral bodies were weighed before and after ashing. We calculated BMD with the help of the vertebral body volume measured in the fpVCT.

\section{Statistical analysis}

Differences between all groups were analyzed by two-way ANOVA. A Bonferroni post hoc test was used to examine interactions (Prism TM, GraphPad, San Diego, USA). A $p$ value $<0.05$ was considered statistically significant. The differences between the weight and size of rats used in the compression test were evaluated by the ratio between the absolute values of the biomechanical test and the volume of each lumbar vertebral body. The vertebral body volume was determined using fpVCT.

\section{Results}

All 60 rats were able to be used for analysis. At the beginning of the experiment, the rats had nearly the same body weight. At the end of the evaluation period, the treated rats had a lower body weight compared to their control groups, though these changes were not significant. At the end of the treatment period, vibrated rats had a significant decrease in body weight of $4.2 \mathrm{~g}$ in SHAM Vib. and $9.4 \mathrm{~g}$ in OVX Vib. rats $(p=0.0017)$. The body weight of untreated animals increased by $4.1 \mathrm{~g}$ (SHAM) and $4.4 \mathrm{~g}$ (OVX). Compared to SHAM rats, OVX rats had an increased body weight $(p<0.0001)$. The uterus wet weight of SHAM rats was significantly higher $(p<0.0001)$ compared to OVX rats (Table 1).

\section{Serum analyses}

The serum concentration of alkaline phosphatase was significantly different between SHAM and OVX rats $(p \leq$ 0.0001 ). There was no significant difference between treated and untreated animals. The concentration of osteocalcin was not significantly different between SHAM and OVX or between treated and untreated animals (Table 1).

\section{Biomechanical testing}

Biomechanical properties improved in the SHAM group. Maximum load $(p=0.0043)$ and Young's modulus $(p=$ $0.0008)$ were significantly enhanced compared to OVX rats. Although the yield load of SHAM rats had higher mean values, the difference failed to reach significance. Whole-body vibration induced improved biomechanical properties in both groups. A significant improvement was observed for the point of change from elastic to plastic deformation $(p=0.0036)$ consistent with the incidence of the first microcracks (i.e., the yield load). A significant improvement was also observed in Young's modulus $(p=0.0009)$, while the maximum load, which primarily depends on cortical bone parameters, showed higher but non-significant changes in mean values. The treated OVX rats reached $(S)$, or even exceeded $\left(y_{\mathrm{L}}\right)$, the values of the untreated SHAM rats (Table 1, Fig. 3).

\section{Histomorphometry}

In all measured parameters, SHAM rats demonstrated a significant improvement in the histomorphometric evaluation compared to OVX rats ( $p<0.0001$ for all parameters). Whole-body vibration induced a significant improvement of all tested morphologic parameters. Vibration resulted in a significant increase in trabecular bone area $(p=0.0006)$, number of nodes $(p=0.0089)$, trabecular width $(p=0.0317)$, trabecular number $(p=0.0028)$ as well as the cortical percentage $(p=0.0032)$ (Table 1, Fig. 4).

Intravital fluorochrome labeling

We observed clear qualitative differences between SHAM and OVX rats (Fig. 4). In the statistical evaluation, the total apposition bandwidth, the apposition bandwidth per day, and the relative apposition bandwidth were analyzed. The apposition bandwidth was significantly increased in OVX compared to SHAM rats (absolute values $-p=0.0009$, 
Table 1 Results of the study

\begin{tabular}{|c|c|c|c|c|c|c|c|c|c|c|}
\hline & \multicolumn{2}{|c|}{ SHAM } & \multicolumn{2}{|c|}{ SHAM Vib. } & \multicolumn{2}{|l|}{ OVX } & \multicolumn{2}{|l|}{ OVX Vib. } & \multirow{2}{*}{$\begin{array}{l}\text { OVX vs. } \\
\text { SHAM } \\
p \text { value }\end{array}$} & \multirow{2}{*}{$\begin{array}{l}\text { Vib vs. } \\
\text { non vib } \\
p \text { value }\end{array}$} \\
\hline & Mean & STD & Mean & STD & Mean & STD & Mean & STD & & \\
\hline $\begin{array}{l}\text { Body weight } \\
\text { pre-surgery (g) }\end{array}$ & 227.0 & 8.3 & 223.1 & 8.0 & 228.6 & 10.4 & 225.2 & 9.4 & 0.3918 & 0.0900 \\
\hline $\begin{array}{l}\text { Body weight at the } \\
\text { end of the trial }(\mathrm{g})\end{array}$ & 302.4 & 20.9 & 298.3 & 22.3 & 371.1 & 40.8 & 355.5 & 34.7 & $<0.0001$ & 0.2525 \\
\hline Uterus wet weight $(\mathrm{g})$ & 0.584 & 0.153 & 0.556 & 0.156 & 0.098 & 0.019 & 0.101 & 0.030 & $<0.0001$ & 0.6675 \\
\hline $\begin{array}{l}\text { Maximum load } \\
\left(\mathrm{N} / \mathrm{mm}^{3}\right)\end{array}$ & 2.467 & 0.44 & 2.521 & 0.41 & 2.113 & 0.42 & 2.2200 & 0.27 & 0.0043 & 0.1562 \\
\hline Yield load (N/mm $\left.{ }^{3}\right)$ & 1.837 & 0.50 & 2.160 & 0.33 & 1.677 & 0.32 & 2.011 & 0.34 & 0.1564 & 0.0036 \\
\hline $\begin{array}{l}\text { Young's modulus } \\
\left(\mathrm{N} / \mathrm{mm} \mathrm{mm}^{-3}\right)\end{array}$ & 1.531 & 0.35 & 2.205 & 0.58 & 1.404 & 0.23 & 1.528 & 0.38 & 0.0008 & 0.0009 \\
\hline $\begin{array}{l}\text { Trabecular bone area } \\
\left(\mathrm{mm}^{2}\right)\end{array}$ & 7.42 & 1.13 & 7.87 & 1.10 & 5.94 & 1.04 & 6.63 & 1.09 & $<0.0001$ & 0.0006 \\
\hline Trabecular width $\left(\mathrm{m}^{-6}\right)$ & 10.06 & 1.60 & 10.56 & 1.25 & 8.79 & 0.82 & 9.04 & 0.78 & $<0.0001$ & 0.0317 \\
\hline $\begin{array}{l}\text { Number of nodes } \\
\left(\mathrm{n} / \mathrm{mm}^{2}\right)\end{array}$ & 15.59 & 2.79 & 16.49 & 2.02 & 13.55 & 2.36 & 14.65 & 2.55 & $<0.0001$ & 0.0089 \\
\hline $\begin{array}{l}\text { Cortical bone } \\
\text { volume }(\%)\end{array}$ & 64.02 & 6.20 & 67.84 & 4.68 & 58.19 & 6.92 & 59.94 & 6.79 & $<0.0001$ & 0.0032 \\
\hline Trabecular number $(n)$ & 159 & 29.2 & 162 & 26.5 & 138 & 23.8 & 147 & 23.8 & $<0.0001$ & 0.0028 \\
\hline Ash-BMD (mg/cm³ & 1,191 & 107 & 1,291 & 106 & 1,052 & 97 & 1,141 & 59 & $<0.0001$ & 0.0011 \\
\hline $\begin{array}{l}\text { fpVCT - total BMD } \\
\left(\mathrm{mg} / \mathrm{cm}^{3}\right)\end{array}$ & 384 & 30.6 & 390 & 32.0 & 332 & 15.8 & 339.6 & 15.6 & $<0.0001$ & 0.0532 \\
\hline $\begin{array}{l}\text { fpVCT-cancellous } \\
\text { BMD }\left(\mathrm{mg} / \mathrm{cm}^{3}\right)\end{array}$ & 303 & 10.3 & 306 & 6.6 & 286 & 11.7 & 288 & 7.2 & $<0.0001$ & 0.0634 \\
\hline $\begin{array}{l}\text { fpVCT-cortical } \\
\text { BMD }\left(\mathrm{mg} / \mathrm{cm}^{3}\right)\end{array}$ & 512 & 11.6 & 515 & 10.9 & 494 & 10.7 & 500 & 8.9 & $<0.0001$ & 0.0035 \\
\hline
\end{tabular}

The $p$ value of the difference between treated and untreated animals was calculated using a two-way-ANOVA. $p$ values $<0.05$ were considered significant

absolute values per day $-p=0.0026)$. In OVX animals, the trabecular apposition bands had a stronger green $(0$ 18 days) aspect, while the SHAM groups demonstrated a stronger red (18-24 days) aspect. This observation was confirmed in the semi-quantitative evaluation. The calcein green apposition band (0-18 days) was significantly reduced in SHAM compared to OVX rats $(p<0.0001$ for all). The same effect could be observed for the second period (18-24 days), but the apposition bandwidth was still significantly reduced in SHAM compared to OVX rats (absolute values $-p=0.0267$, absolute values per day $-p=$ 0.0269 , relative values $-p=0.0436$ ). No significant differences were observed in the last period. We therefore concluded that, in SHAM rats, the apposition of new bone formation occurred at a later date compared to apposition in OVX animals (Table 2, Fig. 4). In SHAM and OVX animals, there was only a minimal labeling of the endocortical surface. The semi-quantitative evaluation of both the absolute values of the apposition bands and the width of daily bone apposition values increased for treated compared to untreated rats, but these effects were not significant.
Flat-panel volumetric computed tomography

The SHAM group had a significantly improved BMD, cancellous and cortical bone density compared to OVX animals ( $p<0.0001$ for all). Vibration led to an improvement of total BMD, cancellous and cortical BMD (Table 1). The cortical bone density after vibration was significantly improved $(p=0.0035)$, while the $\operatorname{BMD}(p=0.0532)$ and cancellous bone density $(p=0.0634)$ showed improvement; however, the improvement failed to reach significant values.

The main disadvantage of the fpVCT used in this study was the lower spatial resolution compared to the $\mu \mathrm{CT}$. The former method does not allow a detailed description of the trabecular microstructure.

\section{Ashing}

The ash-BMD of SHAM rats was significantly improved compared to OVX rats $(p<0.0001)$. Vibration yielded a significant improvement of ash-BMD in all groups $(p=$ 0.0011). There were no differences between groups before ashing. After ashing, the SHAM-operated animals had 
Fig. 3 Results of the histomorphometry. The $p$ value between treated and untreated animals was calculated using a two-way ANOVA. $p$ values $<0.05$ were considered significant $(* p<0.05$ vs. OVX, $\# p<0.05$ vs. non vib)
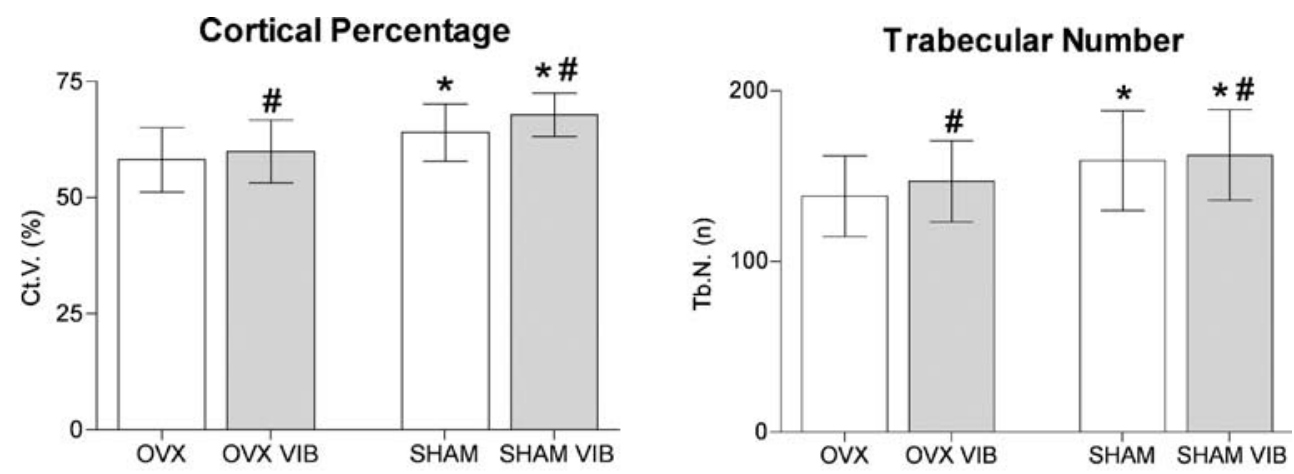

Number of Nodes
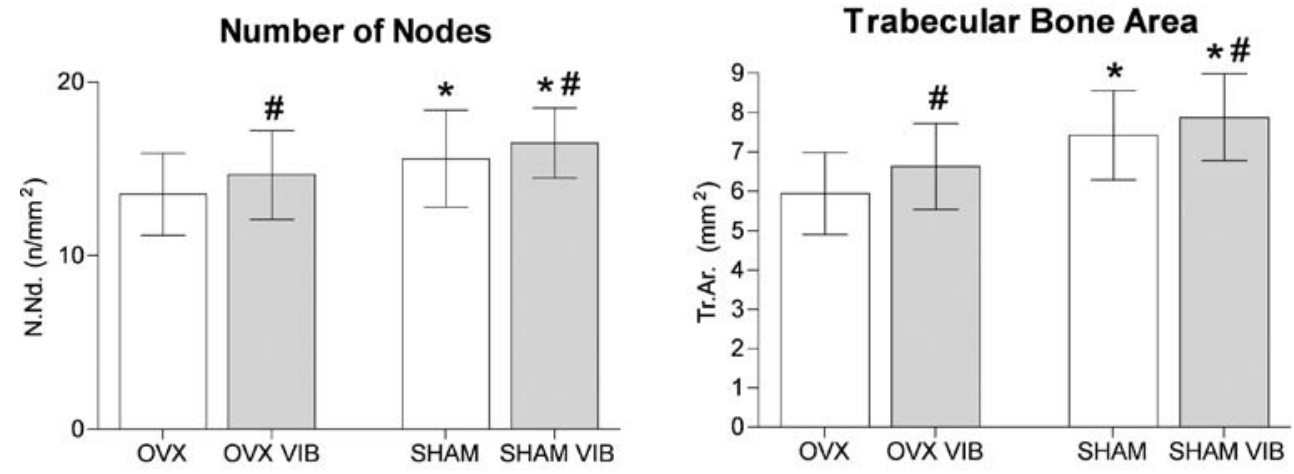

Trabecular Width

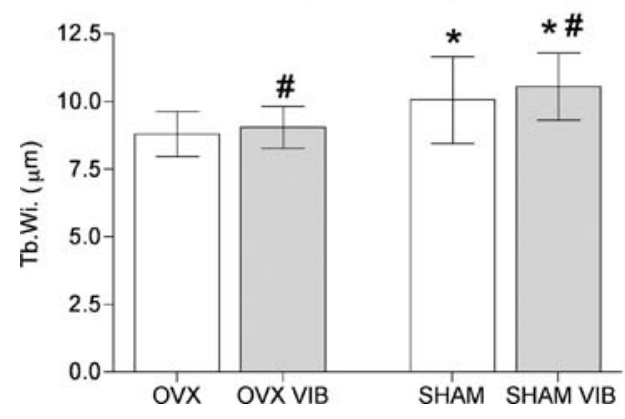

higher ash weights compared to OVX, but these changes were not significant. After calculating the ash-BMD, more differences between the groups were observed (Table 1).

\section{Discussion}

Osteoporosis primarily affects trabecular bone. In humans, the majority of osteoporotic fractures occur in the spine and metaphysis of long bones. In the rat osteopenia model, osteoporosis mainly affects the metaphyseal tibia and lumbar spine [19-23]. Because of the high bone turnover in the upper tibial metaphysis, this bone model might react faster or in a different manner relative to human bones. The clear advantage of analyzing lumbar vertebrae is the opportunity to measure both trabecular as well as cortical bone properties. Vertebral bodies should be observed as a functional unit; their stability is a result of the synergy between a cortical frame and an inner trabecular network.
Thus, both structures resist force. Osteoprotective treatments may influence the trabecular as well as the cortical bone. The evaluation of vertebral body bone strength without the cortical shell can therefore lead to unreliable results.

Information regarding the benefit of the short-term effects of WBVV on lumbar vertebrae in animal models is rare. In this study, we tested the hypothesis that lowmagnitude WBVV after short-term application can stimulate bone formation in SHAM and OVX rats. Most parameters measured in this study resulted in improved bone quality after WBVV treatment. The differences were most pronounced in the biomechanical test, the ashing and the histomorphometric evaluation. Because of technical limitations (lower spatial resolution compared to $\mu \mathrm{CT}$ ), the fpVCT prototype cannot detect all subtle changes of bone structure after short-term WBVV. With this fpVCT prototype, a spatial resolution of approximately $150 \mu \mathrm{m}$ was achieved. The average trabecular thickness in rats is 
Fig. 4 The intravital fluorochrome labeling demonstrated higher bone apposition after whole-body vibration. a SHAM untreated, b SHAM treated, c OVX untreated, $\mathbf{d}$ OVX treated
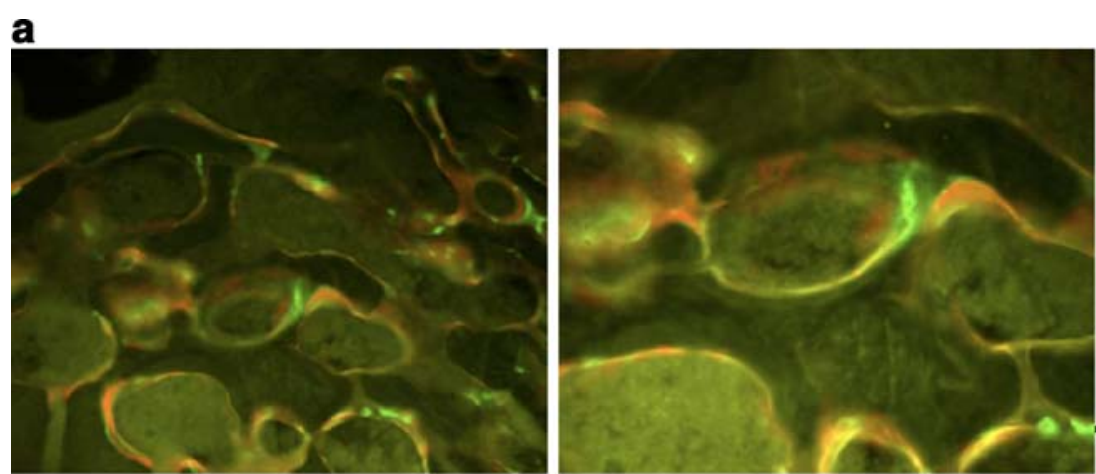

\section{b}
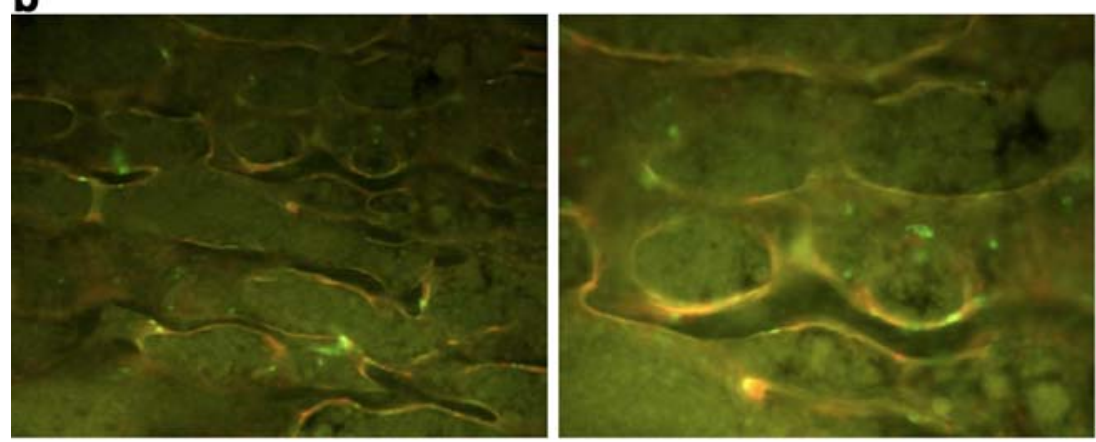

C
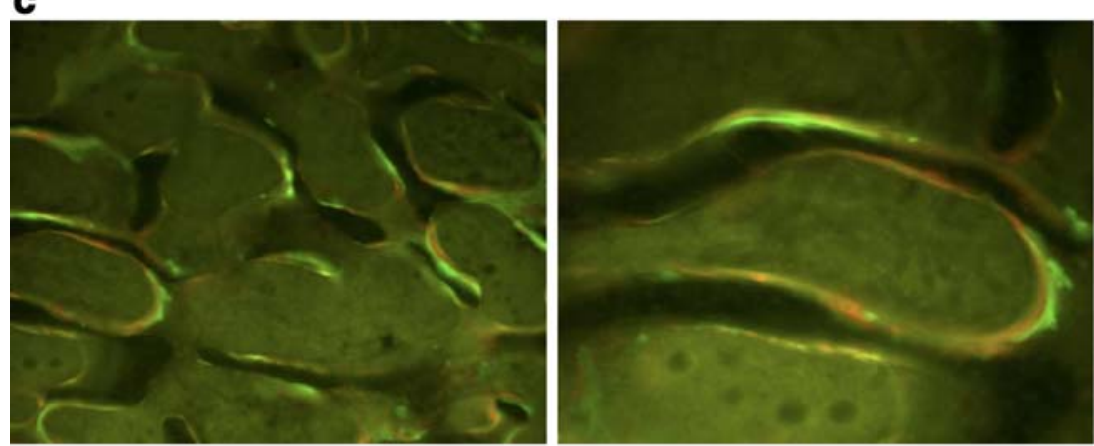

d
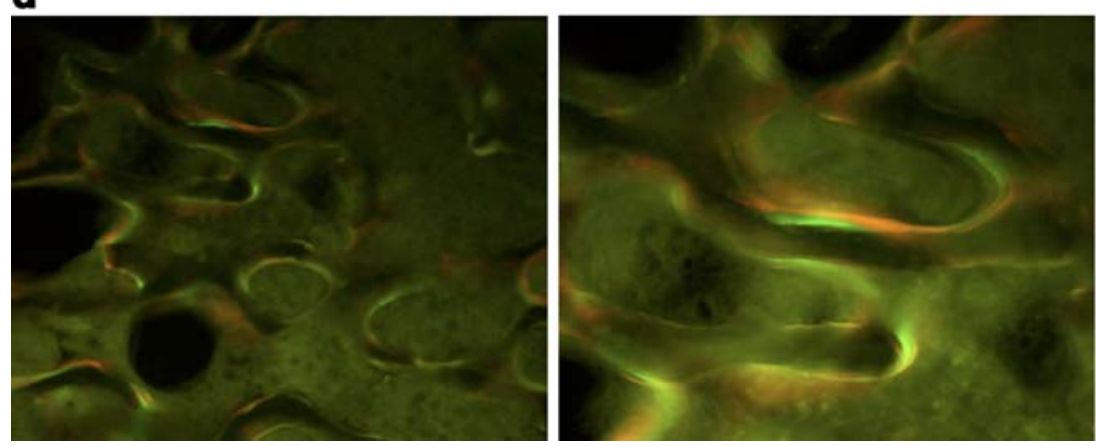

approximately $50 \mu \mathrm{m}$ and the space between them is about $150 \mu \mathrm{m}$. With fpVCT, trabecular destruction can only be detected indirectly. The subtle changes after WBVV should therefore be detected by $\mu \mathrm{CT}$ in the rat osteopenia model. Because of the different proportions of human compared to rat bone, fpVCT would be better able to analyze trabecular microstructures in humans.
The improved trabecular microstructure after WBVV resulted in better biomechanical properties and higher ashBMD values. Similar to previous studies in which vibratory stimuli positively influenced bone mass in post-menopausal women [24], we demonstrated that WBVV can serve as an anabolic signal to a skeleton independent of estrogen level. The results of the presented study are consistent with the 
Table 2 Results of the intravital fluorochrome labeling

\begin{tabular}{|c|c|c|c|c|c|c|c|c|c|c|}
\hline & \multicolumn{2}{|c|}{ SHAM } & \multicolumn{2}{|c|}{ SHAM Vib. } & \multicolumn{2}{|l|}{ OVX } & \multicolumn{2}{|c|}{ OVX Vib. } & \multirow{2}{*}{$\begin{array}{l}\text { OVX vs. SHAM } \\
p \text { value }\end{array}$} & \multirow{2}{*}{$\begin{array}{l}\text { Vib vs. non vib } \\
p \text { value }\end{array}$} \\
\hline & Mean & STD & Mean & STD & Mean & STD & Mean & STD & & \\
\hline \multicolumn{11}{|c|}{ Absolute apposition bandwidth $\left(\mathrm{m}^{-6}\right)$} \\
\hline Calcein green $(\mathrm{d} 0-\mathrm{d} 18)$ & 696 & 275 & 822 & 226 & 1093 & 182 & 1032 & 290 & $<0.0001$ & 0.4829 \\
\hline Alizarin red (d18-d24) & 823 & 271 & 804 & 229 & 889 & 181 & 944 & 274 & 0.0267 & 0.6943 \\
\hline Tetracycline (d24-d35) & 659 & 333 & 641 & 226 & 669 & 219 & 709 & 242 & 0.4267 & 0.8278 \\
\hline Sum & 2,178 & 2,267 & 2,651 & 2,685 & & & & & & \\
\hline \multicolumn{11}{|c|}{ Absolute apposition bandwidth per day $\left(\mathrm{m}^{-6}\right)$} \\
\hline Calcein green $(\mathrm{d} 0-\mathrm{d} 18)$ & 38.6 & 15.3 & 45.7 & 12.5 & 60.7 & 10.1 & 57.3 & 16.1 & $<0.0001$ & 0.4877 \\
\hline Alizarin Red (d18-d24) & 137.2 & 45.2 & 134.1 & 38.2 & 148.2 & 30.2 & 157.3 & 45.6 & 0.0269 & 0.7024 \\
\hline Tetracycline (d24-d35) & 59.9 & 30.3 & 58.3 & 20.5 & 60.8 & 19.9 & 64.5 & 22.0 & 0.4275 & 0.8227 \\
\hline Sum & 235.7 & 238.1 & 269.7 & 279.1 & & & & & & \\
\hline \multicolumn{11}{|c|}{ Relative apposition bandwidth per day (\%) } \\
\hline Calcein green $(\mathrm{d} 0-\mathrm{d} 18)$ & 16.8 & 4.0 & 19.4 & 3.4 & 22.9 & 3.9 & 20.7 & 2.7 & $<0.0001$ & 0.7371 \\
\hline Alizarin red $(\mathrm{d} 18-\mathrm{d} 24)$ & 58.5 & 5.0 & 56.3 & 4.7 & 54.9 & 3.3 & 56.2 & 6.1 & 0.0436 & 0.6052 \\
\hline Tetracycline $(\mathrm{d} 24-\mathrm{d} 35)$ & 24.7 & 7.0 & 24.3 & 4.8 & 22.2 & 4.0 & 23.2 & 5.5 & 0.0831 & 0.8085 \\
\hline
\end{tabular}

The $p$ value of the difference between treated and untreated animals was calculated using a two-way ANOVA. $p$ values $<0.05$ were considered significant

results of Rubin et al. [25], who found an inhibition of BMD decline in the spine following menopause. Gilsanz et al. [26] found an increase in bone of approximately $2 \%$ and an increase in muscle strength of about $5 \%$ in young women with low BMD after 1 year of vibration. These results are in contrast to those reported by Rubinacci et al. [27], who found that WBVV requires the absence of gonadal estrogens to be anabolic. In their study, they analyzed the effect of vibratory stimuli on rat tibiae. The discrepancy in the results of these studies could result from a different allocation of estrogen receptor $\alpha$ in vertebrae compared to tibiae, which has been shown to have increased expression in response to mechanical strain in vitro and in vivo [28, 29]. Torvinen et al. [30] did not find any effects after vibration after a 4-min vibration program in young adults. The short duration of treatment could, however, explain their negative results.

The evaluation of fluoroscopy labeling confirmed higher bone apposition after the vibratory stimulus. In the present study, OVX rats demonstrated earlier and thicker apposition compared to intact rats. Because of the high bone turnover in osteoporosis, the bones of these rats could react earlier (and thus incorporate label earlier) than in intact rats. An additional reason for the observed phenomenon could be the reduced biomechanical stability of osteoporotic bones due to trabecular deterioration. According to Wolff's law, bone microarchitecture always serves to optimize bone biomechanical strength using the least amount of bone material. The thicker apposition bands are therefore the reaction of the bone to counteract reduced biomechanical strength, while intact rats have no need to improve their bone strength.

The physical and biologic mechanisms that control the adaptation of bone to its loading environment are complex [31] and involve the interaction of pathways mediated through gravity, muscle contractions, and physical activity. There is also a genetic component that defines the musculoskeletal system's susceptibility to mechanical signals [32]. The strain signals observed here as well as in previous studies are below those that are imposed on the skeleton by vigorous exercise. A common perception of skeletal adaption to exercise is that mechanical loads must be great in order to augment bone mass. This will induce bone strains that are sufficient to cause microscopic damage and stimulate bone formation through the repair of damaged tissue [33]. In contrast to these loads, extremely low-level, high-frequency vibration has been shown to be anabolic to bone tissue [34]. The low-level, high-frequency loads were significantly more robust than those experienced during minimal activities of daily life [35].

Though the exact steps in the mechanotransduction pathway are not fully established, loading results in matrix deformation and creates hydrostatic pressure gradients within the fluid-filled lacunar canalicular network [36]. The pressure gradients are equilibrated via the movement of extracellular fluid from regions of high pressure to regions of low pressure. Shear stresses are generated on the plasma membranes of resident osteocytes, bone-lining cells, and osteoblasts. These cells are sensitive to fluid shear stresses and respond via initiating a cascade of cellular events. As 
strain rate is directly related to loading frequency, the rate at which bone deformation occurs increases with higher loading frequency. Warden et al. [37] found that loading frequencies greater than $10 \mathrm{~Hz}$ serve no benefit to cortical bone. Furthermore, they showed that fluid flow and the transduction process become less efficient at higher frequencies. Fluid particle movement could be suboptimal and may not match the externally applied mechanical stimulus. This effect may explain the less positive effects of WBVV on cortical bone parameters, e.g., maximum load, cortical volume, or cortical bone density. Fluid particle movement could also underlie the decreased fluoroscopy labeling at the endocortical surface observed in this study. Similar to Warden et al. [35], we hypothesize that a synergistic effect of the mechanotransduction pathway in combination with muscle stimulation is responsible for the observations made here. Higher muscle activity results in increased bone formation, but these effects could be lower in comparison to WBVV at frequencies of 5$10 \mathrm{~Hz}$. Garman et al. [38], who also observed an increase in trabecular bone after whole-body vibration, demonstrated that bone cells can detect physical stimuli directly in the absence of significant bone deformation. In their study, the oscillatory motion resulted in increased trabecular bone without altering weight bearing characteristics.

A limitation of this study was the use of only one frequency, one direction of vibration, and one amplitude. The technique of WBVV used in this study was selected according to the results of Judex et al. [7], who demonstrated a significant increase of bone mass after WBV at $90 \mathrm{~Hz}$ compared to $45 \mathrm{~Hz}$ in rat tibiae. The results presented herein may not apply to subjects with older bones, nor may they apply to other bone regions, to males or even to humans. Our findings apply to a specific type of mechanical stimulus, and it is likely that other types of vibration may result in varying effects on bone. Furthermore, rats were not fixed in a special position during vibration. In studies performed by Vershueren et al. [24] and Torvinen et al. [30], patients performed different actions during vibration. The test rats in this study moved freely on the vibration platform. It is possible that vibratory stimuli could change according to body posture. The effects could also potentially be dampened by the viscoelastic nature of the muscle-tendon apparatus [39]. In contrast to other groups that had animals laying down on the vibration platform, the rats in this study tended to run all over the cage, attempting to escape from the cage by standing on their hind feet and thereby receiving greater axial load.

The presented data and data from other studies suggest that mechanical signals may have the potential to influence both bone and muscle. Considering the importance of muscle strength and function to the incidence of falls and fall-related injuries, whole-body vertical vibration may be useful in reducing the risk for osteoporosis-related fractures [40]. Many questions remain regarding the benefit of whole-body vibration on the musculoskeletal system. It is not known, however, whether the effects will persist over time or whether such a treatment can help reduce falls and osteoporosis-associated fractures. Nevertheless, this nondrug method shows potential for the treatment of osteoporosis. Further studies are needed to evaluate the optimal loading frequency, intensity, duration for treatment, potential side effects (e.g., lower back pain), and the rate of recurrence.

\section{Conflicts of interest None.}

Open Access This article is distributed under the terms of the Creative Commons Attribution Noncommercial License which permits any noncommercial use, distribution, and reproduction in any medium, provided the original author(s) and source are credited.

\section{References}

1. Siris E, Adachi JD, Lu Y et al (2002) Effects of raloxifene on fracture severity in postmenopausal women with osteoporosis: results from the MORE study. Multiple Outcomes of Raloxifene Evaluation. Osteoporos Int 13:907-913

2. Lindsay R, Gallagher JC, Kleerekoper M et al (2005) Bone response to treatment with lower doses of conjugated estrogens with and without medroxyprogesterone acetate in early postmenopausal women. Osteoporos Int 16:372-379

3. Genant HK, Delmas PD, Chen P et al (2007) Severity of vertebral fracture reflects deterioration of bone microarchitecture. Osteoporos Int 18:69-76

4. Marcus R, Feldman D, Kelsey J (eds) (2007) Osteoporosis. Elsevier Science \& Technology, St. Louis

5. Turner CH, Takano Y, Owan I (1995) Aging changes mechanical loading thresholds for bone formation in rats. J Bone Miner Res 10:1544-1549

6. Oxlund H, Andersen NB, Ortoft G et al (1998) Growth hormone and mild exercise in combination markedly enhance cortical bone formation and strength in old rats. Endocrinology 139:1899-1904

7. Rubin C, Turner AS, Müller R et al (2002) Quantity and quality of trabecular bone in the femur are enhanced by a strongly anabolic, noninvasive mechanical intervention. J Bone Miner Res 17:349357

8. Rubin C, Turner AS, Mallinckrodt C et al (2002) Mechanical strain, induced noninvasively in the high-frequency domain, is anabolic to cancellous bone, but not cortical bone. Bone 30:445452

9. Flieger J, Karachalios T, Khaldi L et al (1998) Mechanical stimulation in the form of vibration prevents postmenopausal bone loss in ovariectomized rats. Calcif Tissue Int 63:510-514

10. Judex S, Lei X, Han D et al (2007) Low-magnitude mechanical signals that stimulate bone formation in the ovariectomized rat are dependent on the applied frequency but not on the strain magnitude. J Biomech 40:1333-1339

11. Hadjiargyrou M, McLeod K, Ryaby JP et al (1998) Enhancement of fracture healing by low intensity ultrasound. Clin Orthop Relat Res 355:216-229 
12. Goodship AE (2008) Genetically modified mechanostats: implications for skeletal competence? J Musculoskelet Neuronal Interact 8:10-11

13. Thompson DD, Simmons HA, Pirie CM et al (1995) FDA guidelines and animal models for osteoporosis. Bone 17:125-133

14. Wronski TJ, Lowry PL, Walsh CC et al (1985) Skeletal alterations in ovarectomized rats. Calcif Tiss Int 37:324-328

15. Stürmer EK, Seidlová-Wuttke D, Sehmisch S et al (2006) Standardized bending and breaking test for the normal and osteoporotic metaphyseal tibias of the rat: effect of estradiol, testosterone, and raloxifene. J Bone Miner Res 21:89-96

16. Sturmer KM (1980) Mikroradiographie des Knochens, Technik, Aussagekraft und Planimetrie. Hefte Unfallheilk 148:247-251

17. Parfitt AM, Drezner MK, Glorieux FH et al (1987) Bone histomorphometry: standardization of nomenclature, symbols, and units. Report of the ASBMR Histomorphometry Nomenclature Committee. J Bone Miner Res 2:595-610

18. Sehmisch S, Dullin C, Zaroban A et al. (2008) The use of flat panel volumetric computed tomography (fpVCT) in osteoporosis research. Academic Radiology in press

19. Ikeda S, Tsurukami H, Ito $\mathrm{M}$ et al (2001) Effect of trabecular bone contour on ultimate strength of lumbar vertebra after bilateral ovariectomy in rats. Bone 28:625-633

20. Yao W, Hadi T, Jiang Y et al (2005) Basic fibroblast growth factor improves trabecular bone connectivity and bone strength in the lumbar vertebral body of osteopenic rats. Osteoporos Int 16:1939-1947

21. Ke HZ, Shen VW, QI H et al (1998) Prostaglandin E2 increase bone strength in intact rats and in ovarectomized rats with established osteopenia. Bone 23:249-255

22. Mosekilde L, Thomsen JS, Orhii PB et al (1999) Additive effect of voluntary exercise and growth hormone treatment on bone strength assessed at four different skeletal sites in an aged rat model. Bone 24:71-80

23. Chachra D, Kasra M, Vanin CM et al (1995) The effect of different hormone replacement therapy regimes on the mechanical properties of rat vertebra. Calcif Tissue Int 56:130-134

24. Verschueren SM, Roelants M, Delecluse C et al (2004) Effect of 6-month whole body vibration training on hip density, muscle strength, and postural control in postmenopausal women: a randomized controlled pilot study. J Bone Miner Res 19:352-359

25. Rubin C, Recker R, Cullen D et al (2004) Prevention of postmenopausal bone loss by a low-magnitude, high-frequency mechanical stimuli: a clinical trial assessing compliance, efficacy, and safety. J Bone Miner Res 19:343-351
26. Gilsanz V, Wren TA, Sanchez M et al (2006) Low-level, highfrequency mechanical signals enhance musculoskeletal development of young women with low BMD. J Bone Miner Res 21:1464 1474

27. Rubinacci A, Marenzana M, Cavani F et al (2008) Ovariectomy sensitizes rat cortical bone to whole-body vibration. Calcif Tissue Int 82:316-326

28. Lee KC, Jessop H, Suswillo R et al (2004) The adaptive response of bone to mechanical loading in female transgenic mice is deficient in the absence of oestrogen receptor-alpha and -beta. J Endocrinol 182:193-201

29. Saxon LK, Turner CH (2005) Estrogen receptor beta: the antimechanostat? Bone 36:185-192

30. Torvinen S, Kannus P, Sievänen H et al (2003) Effect of 8-month vertical whole body vibration on bone, muscle performance, and body balance: a randomized controlled study. J Bone Miner Res 18:876-884

31. Karsenty G (2003) The complexities of skeletal biology. Nature 423:316-318

32. Judex S, Garman R, Squire M et al (2004) Genetically linked sitespecificity of disuse osteoporosis. J Bone Miner Res 19:607-613

33. Burr DB, Forwood MR, Fyhrie DP et al (1997) Bone microdamage and skeletal fragility in osteoporotic and stress fractures. $\mathrm{J}$ Bone Miner Res 12:6-15

34. Eisman JA (2001) Good, good, good... good vibrations: the best option for better bones? Lancet 358:1924-1925

35. Fritton SP, McLeod KJ, Rubin CT (2000) Quantifying the strain history of bone: spatial uniformity and self-similarity of lowmagnitude strains. J Biomech 33:317-325

36. Duncan RL, Turner CH (1995) Mechanotransduction and the functional response of bone to mechanical strain. Calcif Tissue Int $57: 344-358$

37. Warden SJ, Turner CH (2004) Mechanotransduction in the cortical bone is most efficient at loading frequencies of $5-10 \mathrm{~Hz}$. Bone 34:261-270

38. Garman R, Rubin C, Judex S (2007) Small oscillatory accelerations, independent of matrix deformations, increase osteoblast activity and enhance bone morphology. PLoS ONE 25:e653

39. Castillo AB, Alam I, Tanaka SM et al (2006) Low-amplitude, broad-frequency vibration effects on cortical bone formation in mice. Bone 39:1087-1096

40. Cummings SR, Nevitt MC, Browner WS et al (1995) Risk factors for hip fracture in white women. Study of Osteoporotic Fractures Research Group. N Engl J Med 332:767-773 